\title{
Efficacy of premedication with intranasal dexmedetomidine for removal of inhaled foreign bodies in children by flexible fiberoptic bronchoscopy: a randomized, double-blind, placebo-controlled clinical trial
}

Yanmei $\mathrm{Bi}^{1,2}$, Yushan $\mathrm{Ma}^{1,2}$, Juan $\mathrm{Ni}^{1,2}$ and Lan $\mathrm{Wu}^{1,2^{*}}$ (D)

\begin{abstract}
Background: Tracheobronchial foreign body aspiration in children is a life-threatening, emergent situation. Currently, the use of fiberoptic bronchoscopy for removing foreign bodies is attracting increasing attention. Oxygen desaturation, body movement, laryngospasm, bronchospasm, and breath-holding are common adverse events during foreign body removal. Dexmedetomidine, as a highly selective $a_{2}$-adrenergic agonist, produces sedative and analgesic effects, and does not induce respiratory depression. We hypothesized that intranasal dexmedetomidine at $1 \mu \mathrm{g} \mathrm{kg}-1$ administered $25 \mathrm{~min}$ before anesthesia induction can reduce the incidence of adverse events during fiberoptic bronchoscopy under inhalation general anesthesia with sevoflurane.

Methods: In all, 40 preschool-aged children (6-48 months) with an American Society of Anesthesiologists physical status of I or II were randomly allocated to receive either intranasal dexmedetomidine at $1 \mu \mathrm{g} \cdot \mathrm{kg}-1$ or normal saline at $0.01 \mathrm{ml} \mathrm{kg}{ }^{-1} 25 \mathrm{~min}$ before anesthesia induction. The primary outcome was the incidence of perioperative adverse events. Heart rate, respiratory rate, parent-child separation score, tolerance of the anesthetic mask, agitation score, consumption of sevoflurane, and recovery time were also recorded.

Results: Following pre-anesthesia treatment with either intranasal dexmedetomidine or saline, the incidences of laryngospasm (15\% vs. $50 \%)$, breath-holding (10\% vs. $40 \%)$, and coughing (5\% vs. $30 \%)$ were significantly lower in patients given dexmedetomidine than those given saline. Patients who received intranasal dexmedetomidine had a lower parent-child separation score $(P=0.017)$, more satisfactory tolerance of the anesthetic mask $(P=0.027)$, and less consumption of sevoflurane ( $38.18 \pm 14.95 \mathrm{vs} .48 .03 \pm 14.45 \mathrm{ml}, P=0.041)$. The frequency of postoperative agitation was significantly lower in patients given intranasal dexmedetomidine $(P=0.004)$, and the recovery time was similar in the two groups.

\footnotetext{
* Correspondence: Iwu2019@163.com

'Department of Anesthesiology, West China Second University Hospital,

Sichuan University, Chengdu, Sichuan Province, China

${ }^{2}$ Key Laboratory of Birth Defects and Related Diseases of Women and

Children (Sichuan University), Ministry of Education, Chengdu, Sichuan

Province, China
}

(c) The Author(s). 2019 Open Access This article is distributed under the terms of the Creative Commons Attribution 4.0 International License (http://creativecommons.org/licenses/by/4.0/), which permits unrestricted use, distribution, and reproduction in any medium, provided you give appropriate credit to the original author(s) and the source, provide a link to the Creative Commons license, and indicate if changes were made. The Creative Commons Public Domain Dedication waiver (http://creativecommons.org/publicdomain/zero/1.0/) applies to the data made available in this article, unless otherwise stated. 
(Continued from previous page)

Conclusions: Intranasal dexmedetomidine $1 \mu \mathrm{g} \cdot \mathrm{kg}^{-1}$, with its sedative and analgesic effects, reduced the incidences of laryngospasm, breath-holding, and coughing during fiberoptic bronchoscopy for FB removal. Moreover, it reduced postoperative agitation without a prolonged recovery time.

Trail registration: The study was registered with the Chinese Clinical Trial Registry (registration number: ChiCTR1800017273) on July 20, 2018.

Keywords: Foreign body, Fiberoptic bronchoscopy, Dexmedetomidine

\section{Background}

Tracheobronchial foreign body (FB) aspiration in children may be a life-threatening, emergent situation [1]. Undiagnosed or delayed treatment of a tracheobronchial FB may result in pneumonia, atelectasis, a lung abscess, or fatal airway obstruction [2-4]. Prompt, successful removal of an FB is associated with fewer complications and deaths $[5,6]$. Rigid bronchoscopy is the main diagnostic and therapeutic procedure for patients suspected to have aspirated a foreign body. It allows an excellent control of the airway, provides a large working channel and permits the removal of foreign bodies and thick mucus plug. The use of fiberoptic bronchoscopy to remove tracheobronchial FBs is currently attracting increased attention [7, 8]. The flexible bronchoscopy compared with the rigid bronchoscope is relatively atraumatic, allows the visualization of the upper lobes as well as the natural dynamics of the palate and larynx. The procedure is performed via a laryngeal mask airway (LMA) under general anesthesia. Oxygen desaturation, body movements, laryngospasm, bronchospasm, and breath-holding are common adverse events during FB removal [2, 9].

Dexmedetomidine, a highly selective $\alpha_{2}$-adrenergic agonist, provides sedation without respiratory depression. Used as a preoperative medication, it reduces preoperative anxiety $[10,11]$, lowers the anesthetic requirement, and deepens the level of anesthesia [12, 13]. Several studies have evaluated the sedative effect of intravenous infusion of dexmedetomidine during fiberoptic bronchoscopy and confirmed that this agent is useful for reducing intratracheal stimuli (by decreasing the incidence of coughing, breath-holding, and laryngospasm) and enhancing patients' degree of comfort without the risk of respiratory depression [14-16]. Nevertheless, the patient's recovery time is significantly prolonged by intravenous infusion of dexmedetomidine [15]. It has been reported that the plasma concentrations of dexmedetomidine approaches $100 \mathrm{pg} \cdot \mathrm{ml}^{-1}$ (the low end reported for sedative efficacy) within $20 \mathrm{~min}$ of intranasal administration of atomized dexmedetomidine $1 \mu \mathrm{g} \cdot \mathrm{kg}^{-1}$ in children [17], thereby producing satisfactory sedation before anesthesia induction [18]. The effect of premedication with intranasal dexmedetomidine on reducing the incidence of adverse events during flexible bronchoscopy in children, however, remains undetermined.

This prospective, randomized, double-blind, placebocontrolled study was performed to evaluate whether intranasal dexmedetomidine at a dose of $1 \mu \mathrm{g} \cdot \mathrm{kg}^{-1}$ administered $25 \mathrm{~min}$ before anesthesia induction can reduce the incidence of adverse events during fiberoptic bronchoscopy under sevoflurane inhalation general anesthesia.

\section{Methods}

This study adheres the applicable CONSORT guidelines. This prospective, randomized, double-blind, placebocontrolled, single-center clinical trial was conducted at the West China Second University Hospital (Sichuan University, Chengdu, Sichuan Province, China). The study was registered with the Chinese Clinical Trial Registry (\#ChiCTR1800017273). The China Ethics Committee of Registering Clinical Trials approved the study protocol (\#ChiECRCT-20180113). The parents or legal guardians of each patient were supplied with comprehensive information by one of the investigators, regarding the study's risk, objectives, and procedures. The parents/legal guardians signed informed consent before the patient's inclusion in the study.

\section{Patients}

We enrolled 40 children (age 6-48 months) whose American Society of Anesthesiologists physical status was I or II and who were undergoing FB removal via fiberoptic bronchoscopy during the period from August 10 to December 25, 2018. Patients with congenital disease, a family history of malignant hyperthermia, coagulation disorders, asthma, severe preoperative respiratory impairment (i.e., single-lung emphysema or other type of severe atelectasis), and/or allergy to anesthetics were excluded from the study.

In preparation, all patients fasted from solids for $6 \mathrm{~h}$, breast milk for $4 \mathrm{~h}$, and clear fluids for $2 \mathrm{~h}$ before intervention. They were premedicated with atropine at $10 \mu \mathrm{g} \cdot \mathrm{kg}-1$ i.v. $30 \mathrm{~min}$ before the induction of 
anesthesia. The patients were randomly assigned to one of two groups (Dexmedetomidine (DEX) group and control group) using a simple computerized concealedenvelope method. At $25 \mathrm{~min}$ before anesthesia induction, the patients were administered either intranasal dexmedetomidine (20,171,202; Nhwa Pharmaceutical Co., Ltd., Jiangsu, China) $1 \mu \mathrm{g} \cdot \mathrm{kg}^{-1}(100 \mu \mathrm{g}$ in $1 \mathrm{ml})$ or intranasal normal saline $0.01 \mathrm{ml} \cdot \mathrm{kg}^{-1}$ (Fig. 1). The intranasal drugs were prepared by a dispensing nurse of our department, then administered by a doctor who was unware of patient randomization.

\section{Fiberoptic bronchoscopy}

Anesthesia was induced via mask using 5-8\% sevoflurane in $100 \%$ oxygen at $6 \mathrm{~L} \cdot \mathrm{min}^{-1}$ until the BIS decreased to 40 or 4 mins after consciousness extinction and EtSevo concentration maintained at the same level $(\geq 1.3 \mathrm{MAC})$, at which point the LMA (Henan Tuoren Medical Equipment CO., Ltd.; common LMA-classic) was inserted. Anesthesia was maintained using 3-6\% sevoflurane in fresh gas at $4 \mathrm{~L} \cdot \mathrm{min}^{-1}$ with the BIS at 40-60. The external diameters of the two widely used flexible bronchoscopes for FBs removal were $2.8 \mathrm{~mm}$ and $4.0 \mathrm{~mm}$, respectively. At the beginning of the procedure, lidocaine $2 \mathrm{mg} \cdot \mathrm{Kg}^{-1}$ was sprayed on the epiglottis and larynx. FBs were removed in an FB basket (Boston Scientific Corporation; Zero Tip ${ }^{\mathrm{Tm}}$ Airway Retrieval Basket; OD $1.0 \mathrm{~mm}$ ) through the bronchoscope's suction channel, the sizes of the channels were $1.2 \mathrm{~mm}$ and $2.0 \mathrm{~mm}$ for $2.8 \mathrm{~mm}$ and $4.0 \mathrm{~mm}$ bronchoscopies (Fig. 2). At the end of the procedure, before withdrawing the fiberoptic bronchoscope from the trachea, acetylcysteine was sprayed into the trachea via the bronchoscope. Sevoflurane was discontinued after completion of the procedure, and the patient was allowed to spontaneously breathe $100 \%$ oxygen at $6 \mathrm{~L} \cdot \mathrm{min}^{-1}$. The LMA was removed when the patient moved spontaneously or exhibited a jaw thrust. After removing the LMA, the child was transferred to the postoperative care unit (PACU) for recovery, where he or she was given oxygen at $4-6 \mathrm{~L} \cdot \mathrm{min}^{-1}$ via mask, and underwent heart rat (HR) and oxygen saturation $\left(\mathrm{SpO}_{2}\right)$ monitoring. The patient was discharged from the PACU when the $\mathrm{SpO}_{2}$ had stabilized at $>92 \%$ for 10 min on room air.

\section{Monitoring}

Routine patient monitoring included various measurements, including $\mathrm{SpO}_{2}$, respiratory rate (RR), HR, end-

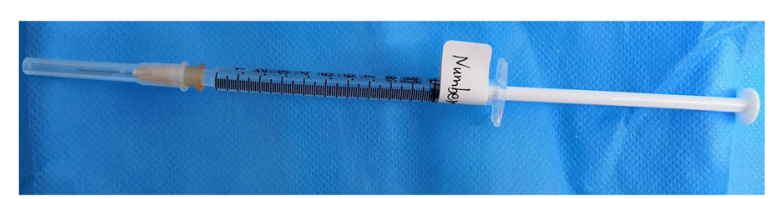

Fig. 1 Dexmedetomidine $100 \mu \mathrm{g} \cdot \mathrm{ml}^{-1}$ or $1-\mathrm{ml}$ normal saline in $1-\mathrm{ml}$ syringe ready for intranasal administration tidal carbon dioxide $\left(\mathrm{EtCO}_{2}\right)$, and end-tidal sevoflurane (EtSevo). Additionally, each patient was monitored for his/her BIS (A-2000; Aspect Medical Systems, Norwood, MA, USA). The $\mathrm{EtCO}_{2}$ was measured by a capnography sensor placed between the L-piece and Bain circuit. The Etsevo was measured by side-stream sensor placed at the breathing circuit filter. The Gas Man anesthesia simulator (Med Man Simulations, Boston, MA, USA) was used to calculate the sevoflurane consumption.

Before induction, the $\mathrm{HR}, \mathrm{RR}$, and $\mathrm{SpO}_{2}$ were recorded at baseline (time 0 , or $\mathrm{T}_{0}$ ). The HR, RR, $\mathrm{SpO}_{2}$, and BIS were then recorded at the following time points: LMA insertion $\left(\mathrm{T}_{\mathrm{LMAi}}\right)$, fiberoptic bronchoscope insertion $\left(\mathrm{T}_{\text {bron }}\right), 5$ min after beginning the procedure $\left(\mathrm{T}_{5 \min }\right)$, the end of the procedure $\left(\mathrm{T}_{\text {end }}\right)$, at LMA removal $\left(\mathrm{T}_{\mathrm{LMAR}}\right)$, 5 min after LMA removal ( $\left.\mathrm{T}_{\text {LMAR5 }}\right)$, and at discharge from the PACU $\left(\mathrm{T}_{\mathrm{dis}}\right)$.

\section{Outcome measurements}

The primary outcome measurements were the incidence of adverse events including: oxygen desaturation, $\mathrm{CO}_{2}$ retention, coughing, body movements, bronchospasm, laryngospasm, breath-holding during the procedure, and coughing in the PACU. Oxygen desaturation was defined as $\mathrm{SpO}_{2}<90 \%$ for 10 s. $\mathrm{CO}_{2}$ retention was defined as $\mathrm{EtCO}_{2} \geq 45 \mathrm{mmHg}$ at the end of the procedure. Emergency treatment measures are shown in Table 1.

The secondary outcome measurements were (1) the separation score at the time of separating the patient from their parents and entrance into the operation room, tolerance of the anesthetic mask during anesthesia induction, the agitation score of each patient in the PACU (Table 2) [19]; (2) consumptions of sevoflurane and other extra medications; (3) anesthesia induction time, Extubation time, and recovery time. Anesthesia induction time was defined as the time from beginning induction to LMA insertion. Extubation time was defined as the time from discontinuing the sevoflurane to LMA removal. Recovery time was defined as the time from discontinuing of sevoflurane to opening of the eyes either spontaneously or by vocal command. All outcome parameters were recorded by another doctor who was unaware of patient randomization.

\section{Sample size calculation}

The sample size was calculated based on the ability to detect a $44.4 \%$ reduction in the incidence of laryngospasm with dexmedetomidine premedication $(55.6 \%$ vs $11.1 \%$, according to our preliminary study) with $80 \%$ power. The level of significance was set at two-sided $\alpha=0.05$. It was then concluded that the sample size required to achieve a statistically significance was 20 samples for each group. 


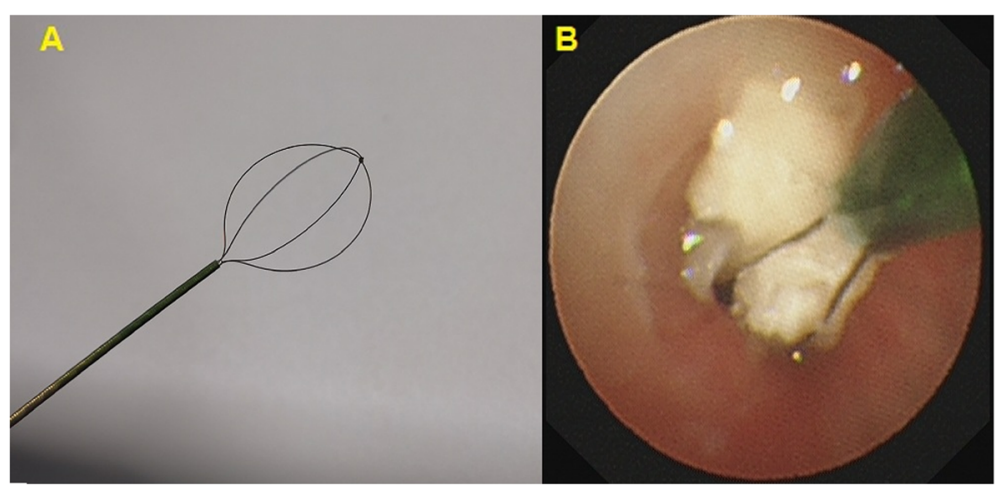

Fig. 2 Foreign body basket used for foreign body removal. a Foreign body basket. b Foreign body was caught in a foreign body basket

\section{Statistical analysis}

A t-test and Wilcoxon's rank-sum test were used to access continuous variables, and the ${ }^{2}$ test to assess categorical variables. The statistical analysis was performed with SPSS software, version 20.0 (IBM Corp., Armonk, NY, USA), $P<0.05$ was considered to indicate statistical significance.

\section{Results}

Altogether, 40 patients were screened, underwent randomization, and completed the study protocol (Fig. 3). There were no differences in patients' characteristics between the two groups except that the HR was significantly lower in patients who were given intranasal dexmedetomidine rather than saline $(136 \pm 21$ vs. $151 \pm$ 14 beats per minute, respectively; $P=0.015)$ (Table 3 ). All of the FBs were organic (walnuts, peanuts, sunflower seeds, melon seeds, raisins, and pears).

Table 1 Emergency treatment for adverse events

\begin{tabular}{|c|c|}
\hline Adverse events & Emergency treatment \\
\hline \multirow[t]{4}{*}{ Laryngospasm } & $\begin{array}{l}\text { Immediately remove the fiberoptic } \\
\text { bronchoscope }\end{array}$ \\
\hline & $\begin{array}{l}\text { Continuous positive airway pressure at } \\
10 \mathrm{cmH}_{2} \mathrm{O}\end{array}$ \\
\hline & $2 \mathrm{mg} \cdot \mathrm{kg}^{-1}$ Propofol iv. \\
\hline & $1 \mathrm{mg} \cdot \mathrm{kg}^{-1}$ Suxamethonium iv. \\
\hline Bronchospasm & 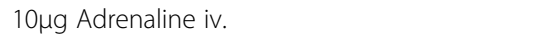 \\
\hline Body movement & $\begin{array}{l}2 \mathrm{mg} \cdot \mathrm{kg}^{-1} \text { Propofol and } 1 \mu \mathrm{g} \cdot \mathrm{kg}^{-1} \text { remifentanil } \\
\text { iv. }\end{array}$ \\
\hline Coughing & $\begin{array}{l}2 \mathrm{mg} \cdot \mathrm{kg}^{-1} \text { Propofol and } 1 \mu \mathrm{g} \cdot \mathrm{kg}^{-1} \text { remifentanil } \\
\text { iv. }\end{array}$ \\
\hline Breath-holding & Manual positive-pressure ventilation \\
\hline \multirow[t]{2}{*}{ Oxygen desaturation } & Increase inhaled oxygen concentration \\
\hline & Manual positive-pressure ventilation \\
\hline $\begin{array}{l}\text { Carbon dioxide } \\
\text { retention }\end{array}$ & Mechanical ventilation \\
\hline
\end{tabular}

Compared with those given saline, the patients given dexmedetomidine had significantly lower incidences [odds ratio (95\% confidence interval)] of laryngospasm [15\% vs. $50 \%$; $0.176(0.039-0.797) ; P=0.018]$, breathholding [10\% vs. $40 \%$; $0.176(0.030-0.924), P=0.028]$, and coughing $[5 \%$ vs. $30 \% ; 0.123 \quad(0.013-1.138)$; $P=0.037$ ] (Fig. 4). The incidence of oxygen desaturation and coughing in the PACU was similar in the two groups.

The RR remained more stable in patients given dexmedetomidine $(P<0.001)$ (Fig. 5$)$. In contrast, the RR was lower in the control group during the procedure, and the controls recovered postoperatively. The incidence of $\mathrm{CO}_{2}$ retention was significantly lower in DEX group than in the control group $(25 \%$ vs. $60 \%$, respectively; $\mathrm{OR}=0.222,95 \% \mathrm{CI}=0.058-0.858 ; P=0.025)$. The mean HR was lower in the DEX group $(P<0.001)$.

Table 2 Clinical scales used for the study

Separation score [19]

1. Excellent; separate easily

2. Good; not clinging, whimpers, easy to calm

3. Fair; not clinging, cries, not calm with reassurance

4. Poor; crying, clinging to their parent

Tolerance of the anesthetic mask during anesthesia induction [19]

1. Excellent; unafraid, cooperative, easy acceptance of mask

2. Good; slight fear of mask, easy to quite

3. Fair; moderate fear, not quite with reassurance

4. Poor; terrified, crying, agitated

Agitation score [19]

1. Sleeping

2. Awake, calm, and cooperative

3. Crying, need consolation

4. Restless, screaming inconsolable

5. Combative, disoriented, trashing

An agitation score of $4-5$ is considered as agitation 


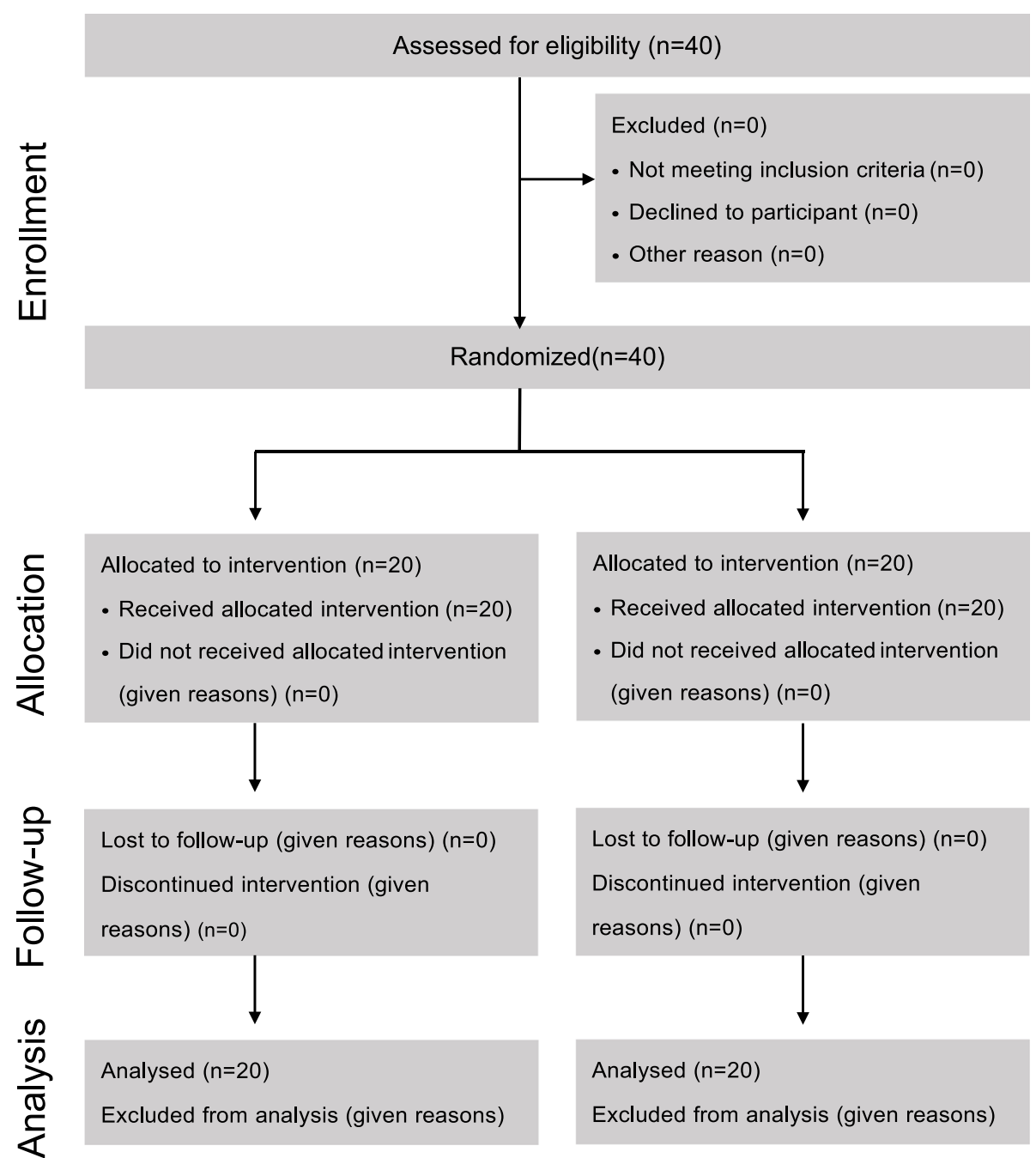

Fig. 3 CONSORT flow diagram

The preoperative separation scores were significantly lower in the DEX group than the control group $(P=0.017)$ (Table 4). Patients receiving dexmedetomidine had better tolerance of the anesthetic mask $(P=0.027)$ and required less time for anesthesia induction $(P=0.015)$. The BIS values of the patients during the procedure were similar in the two groups $(P=0.328)$ (Fig. 6). EtSevo was significantly lower in the DEX group than the control group $(P<0.001)$ (Fig. 5). Consumption of sevoflurane, the agent that maintained anesthesia, was significantly lower in patients receiving dexmedetomidine $(38.18 \pm 14.95$ vs. $48.03 \pm 14.45 \mathrm{ml}$, respectively; $P=0.041$ ). The number of patients need for rescue agents such as propofol and remifentanil was reduced by premedication with intranasal dexmedetomidine $(P=0.003$ and $P=0.008$, respectively) (Table 5).

The extubation time and recovery time were similar in the two groups $(P=0.758$ and $P=0.445$, respectively).
Agitation during recovery occurred in 25\% $(n=5)$ of patients in the DEX group and $70 \%(n=14)$ in the control group $(P=0.004)$. The agitation scores were significantly lower in patients premediated with dexmedetomidine $(P=0.017)$.

\section{Discussion}

Our principal finding was that intranasal dexmedetomidine at a dose of $1 \mu \mathrm{g} \cdot \mathrm{kg}^{-1}$ given $25 \mathrm{~min}$ before anesthesia induction could reduce the incidence of laryngospasm, breath-holding, and coughing during fiberoptic bronchoscopy for FB removal in children. Furthermore, intranasal dexmedetomidine was associated with lower parent-child separation scores, frequency of agitation, and agitation scores. Moreover, it did not prolong the recovery time.

Dexmedetomidine uniquely provides sedative and analgesic effects without respiratory depression $[14,20$, 
Table 3 Demographic characteristics

\begin{tabular}{|c|c|c|c|}
\hline Variables & DEX Group & Control Group & $P$ value \\
\hline Age (months) & $17.2 \pm 6.3$ & $18.0 \pm 6.6$ & 0.737 \\
\hline Sex (male/female) & $15 / 5$ & $14 / 6$ & 0.723 \\
\hline Weight (Kg) & $10.9 \pm 2.2$ & $10.8 \pm 1.2$ & 0.965 \\
\hline Site of foreign body (T/RB/LB/BB) & $1 / 11 / 6 / 2$ & 0/10/9/1 & 0.576 \\
\hline Duration of foreign body aspiration (days) & $5.5(2.3-10.0)$ & $6.0(3.3-10.8)$ & 0.583 \\
\hline Time-lag between diagnosis and retrieval of foreign body (days) & $2(1-3)$ & $2(1-3)$ & 0.904 \\
\hline \multicolumn{4}{|l|}{ Complications } \\
\hline Obstructive emphysema & $11(55)$ & $16(80)$ & 0.091 \\
\hline Pneumonia & $18(90)$ & $20(100)$ & 0.147 \\
\hline Atelectasis & $4(20)$ & $1(5)$ & 0.151 \\
\hline \multicolumn{4}{|l|}{ Baseline value } \\
\hline Heart rate (beats per minute) & $136 \pm 21$ & $151 \pm 14$ & 0.015 \\
\hline Respiratory rate (beats per minute) & $37 \pm 9$ & $37 \pm 5$ & 0.911 \\
\hline Oxygen saturation (\%) & $100(100-100)$ & $100(100-100)$ & 0.583 \\
\hline
\end{tabular}

Date are expressed as mean \pm standard deviation, median (interquartile range) number of patients (percentage). $T$, tracheal; RB, right bronchus; LB, left bronchus; $\mathrm{BB}$, both right and left bronchus. Duration of foreign body aspiration: time from foreign body aspiration to its removal

21], even when administered at doses higher than recommended for sedation [22]. These properties render dexmedetomidine a potentially useful drug during airway surgery. Dexmedetomidine infusion given to remove an airway FB removal attenuates the airway response to fiberoptic bronchoscopy similar to remifentanil [15]. Dexmedetomidine also attenuates the airway response to endotracheal extubation [23, 24].

We also observed a lower incidence of laryngospasm, breath-holding, and coughing during fiberoptic bronchoscopy in patients given dexmedetomidine, suggesting that intranasal dexmedetomidine relieves intratracheal and laryngeal stimuli during this procedure. This effect is possibly mediated via its sedative and analgesic properties. Dexmedetomidine provides analgesia via receptors in the spinal cord, and attenuation of the stress response [25]. As shown in previous studies [10, 11], we also found that premedication with intranasal dexmedetomidine reduced the patients' separation anxiety and resulted in more satisfactory tolerance of the facial mask during anesthesia induction. Reduction in the secretions as a result of less crying during patient separation from the parents and also during induction of anesthesia can reduce the incidence of laryngospasm and coughing.

In contrast to previous reports [23, 24, 26], we observed a similar incidence of oxygen desaturation and coughing in the PACU in our two study groups. The time from FB aspiration to its removal was similar in the

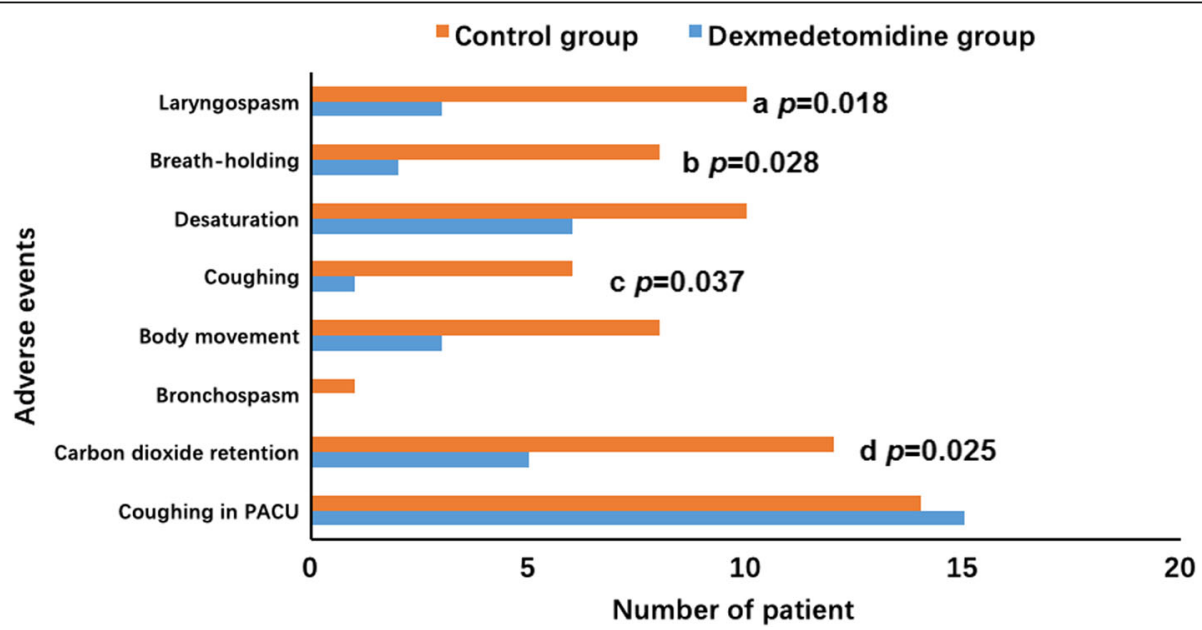

Fig. 4 Incidence of adverse events 

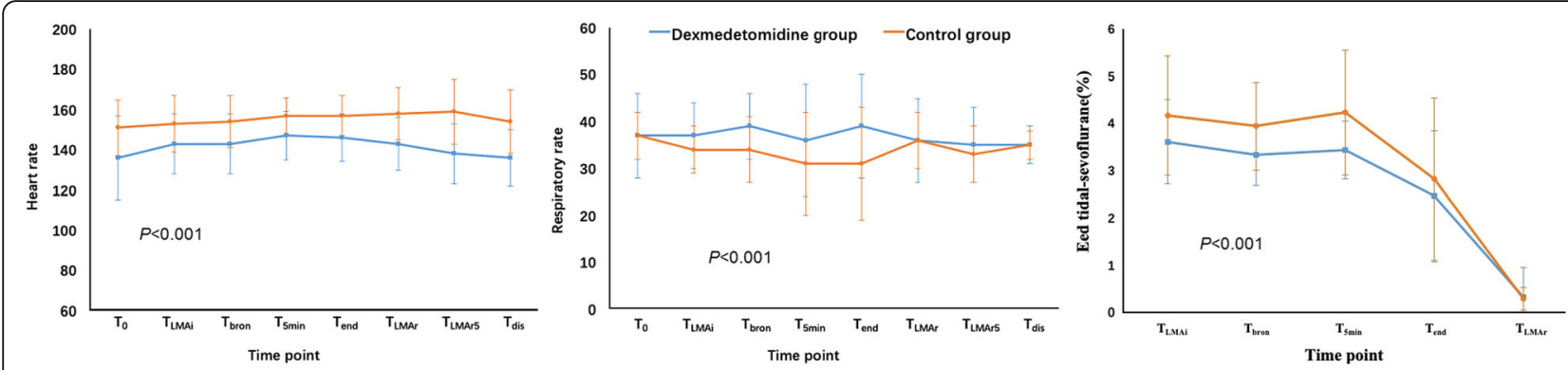

Fig. $5 \mathrm{HR}, \mathrm{RR}$, and Etsevo level at various time points during the study period. $T_{0}$, baseline level before anesthesia; $T_{L M A i}, L M A$ insertion; $T_{\text {bron, }}$ begin of fiberoptic bronchoscopy; $T_{5 \mathrm{~min}}, 5 \mathrm{~min}$ after beginning the procedure; $T_{\text {end, }}$ the end of the procedure; $T_{L M A r}, L M A$ removal; $T_{L M A R 5}, 5$ min after LMA removal

two groups. This similar time lag might cause a similar incidence of pre-procedure pneumonia. Preoperative pneumonia increases respiratory tract secretions, which causes intraoperative hypoxemia, and an increased incidence of coughing in the PACU. The similar incidences in postoperative coughing may have been associated with the intra-tracheal use of acetylcysteine during the procedure.

Similar to a previous study [15], the RR was more stable in patients given dexmedetomidine. In addition, the lower incidence of $\mathrm{CO}_{2}$ retention indicated that dexmedetomidine did not impair the respiratory drive. We observed a lower RR in the control group during the procedure, which must have been associated with inhalation of a higher concentration of sevoflurane and/or greater consumption of propofol and remifentanil. The Et-Sevo was significantly higher in the control group during the procedure, RR decreased as the concentration of sevoflurane increased [27]. Propofol inhibits respiration by acting on GABA receptors [28, 29], whereas remifentanil produces analgesia and respiratory depression by acting on $\mu$ receptors. Moreover, the respiratory rate, $\mathrm{CO}_{2}$ retention, and oxygen saturation are generally maintained during dexmedetomidine sedation in children [30-32].

Compare with the control group, the lower HR during the study period in the DEX group might be explained by the decreased sympathetic outflow and circulating levels of catecholamines caused by dexmedetomidine [33].

In the present study, intranasal dexmedetomidine did not significantly prolong the patients' recovery time, but it did significantly reduce the incidence of postoperative agitation. Emergence agitation occurs frequently in children during recovery from sevoflurane anesthesia. Postoperative restlessness is associated with a risk of selfinjury and is a source of stress for both caregivers and family members. Dexmedetomidine has been used in the management of postoperative agitation because of its sedative and analgesic effects [34].

This new anesthetic agent, dexmedetomidine used alone at clinical doses, has not induced neurotoxicity in juvenile animal models $[35,36]$. It exhibits neuroprotective effects in vitro and attenuates neuro-apoptosis caused by other anesthetic agents, [37, 38]. It is thus considered one of the rare "neuro-safe" anesthetic agents [39] used in infants.

There were few limitations in our study. Firstly, we used only a single dose of dexmedetomidine and thus did not compare the effects of different doses. Yuen et al., however, in a study of patients $<4$ years of age, showed that intranasal dexmedetomidine $1 \mu \mathrm{g} \cdot \mathrm{kg}^{-1} \mathrm{had}$ sedative effects similar to $2 \mu \mathrm{g} \cdot \mathrm{kg}^{-1}$ [21]. Indeed, our preliminary results showed that dexmedetomidine $1 \mu \mathrm{g} \cdot \mathrm{kg}^{-1}$ produces a satisfactory sedative effects without prolonged recovery time, whereas a $2 \mu \mathrm{g} \cdot \mathrm{kg}^{-1}$ or higher dose of dexmedetomidine significantly prolong the recovery time. Secondly, the sample size of this study is small. We only considered the reduction in laryngospasm (as complication) when calculating the sample size, which may not be adequately powered for other complications. Future studies should consider other complications as well such as coughing, body movements, bronchospasm etc. while calculating the sample size.

Table 4 Clinical scales

\begin{tabular}{llll}
\hline Variables & DEX Group & Control Group & $P$ value \\
\hline Separation score2/3/4 & $9 / 9 / 2$ & $2 / 10 / 8$ & 0.017 \\
Tolerance of anesthetic mask 2/3/4 & $2 / 9 / 9$ & $1 / 2 / 17$ & 0.027 \\
Agitation score 2/3/4/5 & $8 / 7 / 4 / 1$ & $1 / 5 / 10 / 4$ & 0.017 \\
\hline
\end{tabular}




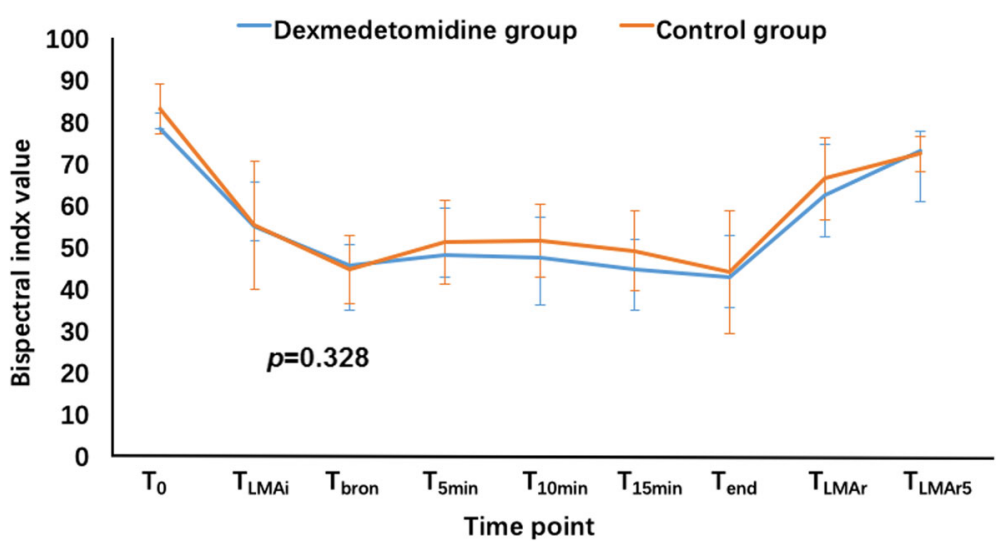

Fig. 6 Bispectral index at various time points during the study period. $T_{0}$, baseline level before anesthesia; $T_{L M A i}, L M A$ insertion; $T_{b r o n}$, begin of fiberoptic bronchoscopy; $T_{5 \mathrm{~min}}, 5 \mathrm{~min}$ after beginning the procedure; $T_{10 \mathrm{~min}}, 10 \mathrm{~min}$ after beginning the procedure; $T_{15 \mathrm{~min}}, 15 \mathrm{~min}$ after beginning the procedure; $T_{\text {end, }}$ the end of the procedure; $T_{L M A r}$ LMA removal; $T_{L M A R}$

\section{Conclusion}

Intranasal dexmedetomidine at $1 \mu \mathrm{g} \cdot \mathrm{kg}^{-1}$, with its sedative and analgesic effects, reduced the incidences of laryngospasm, breath-holding, and coughing during fiberoptic bronchoscopy for FB removal. Moreover, it reduced postoperative agitation without a prolonged recovery time.

\section{Abbreviations}

BB: both right and left bronchus; BIS: Bispectral index; DEX group: dexmedetomidine group; EtCO2: end-tidal carbon dioxide; EtSevo: end-tidal sevoflurane; FB: foreign body; HR: heart rate; LB: left bronchus; LMA: laryngeal mask airway; OD: outside diameter; PACU: postanesthesia care unit; $\mathrm{RB}$ : right bronchus; $\mathrm{RR}$ : respiratory rate; $\mathrm{SpO}_{2}$ : oxygen saturation; T: tracheal

\section{Acknowledgments}

We would like to thank Liping Song, Chunlan Zheng, for helping us prepare the drugs.

\section{Consent to publish}

Not applicable.

\section{Authors' contributions}

YMB: contributed to performing all statistical analyses, drafting the manuscript. YSM: performed all statistical analyses, recruited study participants. JN: performed data acquisition. LW: contributed to the design of the work, and writing the manuscript. All authors have read and approved the manuscript.

\section{Funding}

This study was financially supported by Science and Technology Department of Sichuan Province, China (No. 2018sz0236). The funding agents play no

Table 5 The characteristics and outcome of the fiberoptic bronchoscopies

\begin{tabular}{llll}
\hline Variables & DEX Group & Control Group & $P$ value \\
\hline Size of LMA & $2(2-2)$ & $2(2-2)$ & 0.574 \\
Size of fiberoptic scope (mm) & $4.0(4.0-4.0)$ & $4(4.0-4.0)$ & 0.637 \\
Duration of anesthesia induction (min) & $6(5-6.8)$ & $7(5-10)$ & $17(11-23.8)$ \\
Duration of procedure (min) & $13.5(10.3-20)$ & $6(4-9)$ & 0.015 \\
Extubation time (min) & $6.5(4.3-9.8)$ & $11(9-22)$ & 0.738 \\
Recovery time (min) & $16(8.3-28.8)$ & & 0.758 \\
Propofol & & $12(60 \%)$ & 0.445 \\
$\quad$ No. (\%) & $3(15 \%)$ & $20(20-27.5)$ & 0.003 \\
Dosage (mg) & $30(15-35)$ & & 0.734 \\
Succinylcholine & & $4(20 \%)$ & 0.677 \\
No. (\%) & $3(15)$ & $10(10-25)$ & 0.629 \\
Dosage (mg) & $10(10-10)$ & & 0.008 \\
Remifentanil & & $8(40 \%)$ & $15(10-23.75)$ \\
$\quad$ No. (\%) & $1(5 \%)$ & & 0.667 \\
Dosage (ug) & $10(10-10)$ &
\end{tabular}

Data are expressed as median (interquartile range), number of patients (percentage) 
role in the design of the study and collection, analysis, and interpretation of data and in writing the manuscript.

\section{Availability of data and materials}

The datasets used and/or analyzed during the current study are available from the corresponding author on reasonable request.

\section{Ethics approval and consent to participate}

The protocol was approved by approval by the China Ethics Committee of Registering Clinical Trials (ChiECRCT-20180113). Address: West China Hospital, Sichuan University, NO. 37, Guo Xue Xiang, Chengdu, Sichuan, China. The study was registered with the Chinese Clinical Trial Registry (registration number: ChiCTR1800017273) on July 20, 2018. Website: http://www.chictr. org.cn/edit.aspx?pid=28583\&htm=4. Written informed consent was obtained from the parents or legal guardians of all participants in the trial.

\section{Competing interests}

The authors have no conflicts of interest.

Received: 28 January 2019 Accepted: 25 November 2019

Published online: 02 December 2019

\section{References}

1. Mahajan JK, Rathod KK, Bawa M, Rao KL. Tracheobronchial foreign body aspirations: lessons learned from a 10-year audit. J Bronchol Interv Pulmonol. 2011:18:223-8.

2. Chai J, Wu XY, Han N, Wang LY, Chen WM. A retrospective study of anesthesia during rigid bronchoscopy for airway foreign body removal in children: propofol and sevoflurane with spontaneous ventilation. Paediatr Anaesth. 2014;24:1031-6.

3. Inglis AF, Wagner DV. Lower complication rates associated with bronchial foreign bodies over the last 20 years. Ann Otol Rhinol Larygnol. 1992;101: 61-6.

4. Farrell PT. Rigid bronchoscopy for foreign body removal: anaesthesia and ventilation. Paediatr Anaesth. 2004;14:84-9.

5. Swanson KL. Airway foreign bodies: what's new? Semin Respir Crit Care Med. 2004:25:405-11.

6. Weissberg D, Schwartz I. Foreign bodies in the tracheobronchial tree. Chest. 1987:91:730-3.

7. Sachdev A, Chhawchharia R. Flexible Fiberoptic bronchoscopy in pediatric practice. Indian Pediatr. 2019;56:578-93.

8. Sehgal IS, Dhooria S, Ram B, Singh N, Aggarwal AN, Gupta D, Agarwal R, et al. Foreign body inhalation in the adult population: experience of 25,998 bronchoscopies and systematic review of literature. Respir Care. 2015;60: 1438-48.

9. Gang W, Zhengxia P, Hongbo L, Yonggang L, Jiangtao D, Shengde W, et al. Diagnosis and treatment of tracheobronchial foreign bodies in 1024 children. J Pediatr Surg. 2012;47:2004-10.

10. Sheta SA, Al-Sarheed MA, Abdelhalim AA. Intranasal dexmedetomidine vs midazolam for premedication in children undergoing complete dental rehabilitation: a double-blinded randomized controlled trial. Paediatr Anaesth. 2014;24:181-9.

11. Yuen VM, Hui TW, Irwin MG, Yuen MK. A comparison of intranasal dexmedetomidine and oral midazolam for premedication in pediatric anesthesia: a double-blinded randomized controlled trial. Anesth Analg. 2008;106:1715-21

12. Yao YS, Qian B, Chen YQ, Zhou LJ, Liu J. Intranasal dexmedetomidine premedication reduces the minimum alveolar concentration of sevoflurane for tracheal intubation in children: a randomized trial. J Clin Anesth. 2014;26: 309-14.

13. Ngwenyama NE, Anderson J, Hoernschemeyer DG, Tobias JD. Effects of dexmedetomidine on propofol and remifentanil infusion rates during total intravenous anesthesia for spine surgery in adolescents. Paediatr Anaesth. 2008:18:1190-5

14. Ryu JH, Lee SW, Lee JH, Lee EH, Do SH, Kim CS. Randomized double-blind study of remifentanil and dexmedetomidine for flexible bronchoscopy. Br J Anaesth. 2012;108:503-11.
15. Chen $K Z$, Ye M, Hu CB, Shen X. Dexmedetomidine vs remifentani intravenous anaesthesia and spontaneous ventilation for airway foreign body removal in children. Br J Anaesth. 2014;112:892-7.

16. Liao W, Ma G, Su QG, Fang Y, Gu BC, Zou XM. Dexmedetomidine versus midazolam for conscious sedation in postoperative patients undergoing flexible bronchoscopy: a randomized study. J Int Med Res. 2012:40:1371-80.

17. Miller JW, Balyan R, Dong M, Mahmoud M, Lam JE, Pratap JN, et al. Does intranasal dexmedetomidine provide adequate plasma concentrations for sedation in children: a pharmacokinetic study. Br J Anaesth. 2018;120:105665.

18. Yuen VM, Hui TW, Irwin MG, Yao T-J, Wong GL, Yuen MK. Optimal timing for the administration of intranasal dexmedetomidine for premedication in children. Anaesthesia. 2010:65:922-9.

19. Ozturk T, Erbuyun K, Keles GT, Ozer M, Yuksel H. Tok Demet. The effect of remifentanil on the emergence characteristics of children undergoing FBO for bronchoalveolar lavage with sevoflurane anaesthesia. Eur J Anaesthesiol. 2009:26:338-42.

20. Liao R, Li JY, Liu GY. Comparison of sevoflurane volatile induction/ maintenance anaesthesia and propofol-remifentanil total intravenous anaesthesia for rigid bronchoscopy under spontaneous breathing for tracheal/bronchial foreign body removal in children. Eur J Anaesthesiol. 2010;27:930-4

21. Panzer O, Moitra V, Sladen RN. Pharmacology of sedative-analgesic agents: dexmedetomidine, remifentanil, ketamine, volatile anesthetics, and the role of peripheral mu antagonists. Crit Care Clin. 2009;25:451-69. vii

22. Ramsay MA, Luterman DL. Dexmedetomidine as a total intravenous anesthetic agent. Anesthesiology. 2004;101:787-90.

23. Guler G, Akin A, Tosun Z, Eskitascoglu E, Mizrak A, Boyaci A. Single-dose dexmedetomidine attenuates airway and circulatory reflexes during extubation. Acta Anaesthesiol Scand. 2005:49:1088-91.

24. Turan G, Ozgultekin A, Turan C, Dincer E, Yuksel G. Advantageous effects of dexmedetomidine on haemodynamic and recovery responses during extubation for intracranial surgery. Eur J Anaesthesiol. 2008;25:816-20.

25. Piastra M, Pizza A, Gaddi S, Luca E, Genovese O, Picconi E, et al. Dexmedetomidine is effective and safe during NIV in infants and young children with acute respiratory failure. BMC Pediatr. 2018:18:282.

26. Gao Y, Kang K, Liu H, Jia L, Tang R, Yu K, et al. Effect of dexmedetomidine and midazolam for flexible fiberoptic bronchoscopy in intensive care unit patients: a retrospective study. Medicine (Baltimore). 2017;96:e7090.

27. Mutoh $T$, Kanamaru A, Tsubone $H$, Nishimura R, Sasaki N. Respiratory reflexes in response to upper-airway administration of sevoflurane and isoflurane in anesthetized, spontaneously breathing dogs. Vet Surg. 2001;30: 87-96.

28. Maurg J, Lechamy JB, Laudenbach V, Henzel D, Peytavin G, Desmonts JM. Anesthetics affect the uptake but not the depolarization-evoked release of GABA in rats striatal synaptosomes. Anesthesiology. 1995;82:502-11.

29. Hara M, Kai Y, Ikemoto Y. Enhancement by propofol of the gammaaminobutyric acidA response in dissociated hippocampal pyramidal neurons of the rat. Anesthesiology. 1994:81:988-94.

30. Koroglu A, Demirbilek S, Teksan H, Sagir O, But AK, Ersoy MO. Sedative, haemodynamic and respiratory effects of dexmedetomidine in children undergoing magnetic resonance imaging examination: preliminary results. $\mathrm{Br} J$ Anaesth. 2005:94:821-4.

31. Mahmoud M, Radhakrishman R, Gunter J, Sadhasivam S, Schapiro A, McAuliffe J. Effect of increasing depth of dexmedetomidine anesthesia on upper airway morphology in children. Pediatr Anaesth. 2010;20:506-15.

32. Mahmoud M, Gunter J, Donnelly LF, Wang Y, Nick TD, Sadhasivam S. A comparison of dexmedetomidine with propofol for magnetic resonance imaging sleep studies in children. Anesth Analg. 2009;109:745-53.

33. Arain SR, Ebert TJ. The efficacy, side effects, and recovery characteristics of dexmedetomidine versus propofol when used for intraoperative sedation. Anesth Analg. 2002:95:461-6, Table of contents

34. Kim NY, Kim SY, Yoon HJ, Kil HK. Effect of dexmedetomidine on sevoflurane requirements and emergence agitation in children undergoing ambulatory surgery. Yonsei Med J. 2014;55:209-15.

35. Sanders RD, Sun P, Patel S, Li M, Maze M, Ma D. Dexmedetomidine provides cortical neuroprotection: impact on anaesthetic-induced neuroapoptosis in the rat developing brain. Act Anaesthesiol Scand. 2010:54:710-6. 
36. Perez-Zoghbi JF, Zhu W, Grafe MR, Brambrink AM. Dexmedetomidinemediated neuroprotection against sevoflurane-induced neurotoxicity extends to several brain regions in neonatal rats. $\mathrm{Br} J$ Anaesth. 2017;119: 506-16.

37. Sanders RD, Xu J, Shu Y, Januszewski A, Halder S, Fidalgo A, et al. Dexmedetomidine attenuates isoflurane-induced neurocognitive impairment in neonatal rats. Anesthesiology. 2009;110:1077-85.

38. Li J, Xiong M, Nadavaluru PR, Zuo W, Ye JH, Eloy JD, et al.

Dexmedetomidine attenuates neurotoxicity induced by prenatal propofol exposure. J Neurosurg Anesthesiol. 2016;28:51-64.
39. Andropoulos DB. Effect of anesthesia on the developing brain: infant and fetus. Fetal Diagn Ther. 2018:43:1-11.

\section{Publisher's Note}

Springer Nature remains neutral with regard to jurisdictional claims in published maps and institutional affiliations.
Ready to submit your research? Choose BMC and benefit from:

- fast, convenient online submission

- thorough peer review by experienced researchers in your field

- rapid publication on acceptance

- support for research data, including large and complex data types

- gold Open Access which fosters wider collaboration and increased citations

- maximum visibility for your research: over $100 \mathrm{M}$ website views per year

At $\mathrm{BMC}$, research is always in progress.

Learn more biomedcentral.com/submissions 